\title{
A realização da accountability em pareceres prévios do Tribunal de Contas de Santa Catarina
}

\author{
Arlindo Carvalho Rocha \\ Universidade do Estado de Santa Catarina
}

\begin{abstract}
Este artigo apresenta os resultados da pesquisa que teve como objetivo analisar a realização do potencial de accountability dos pareceres prévios (PP) produzidos pelo Tribunal de Contas do Estado de Santa Catarina (TCE/SC), relativos às contas anuais dos chefes de governos municipais. Tendo como pano de fundo a evidenciação da necessidade de a análise se desdobrar em duas dimensões distintas e a discussão do modelo de análise utilizado, o estudo mostrou que os referidos pareceres prévios pouco realizam do seu potencial de accountability, dado que o TCE/SC pouco avança em relação a esse objetivo, não utilizando nem explorando as possibilidades que a legislação lhe oferece e, portanto, não contribuindo para a materialização da accountability. Por fim, sugerem-se algumas recomendações que poderão servir como diretrizes em futuras pesquisas.
\end{abstract}

Palavras-chave: accountability; pareceres prévios; contas anuais; tribunal de contas; estado de Santa Catarina.

La realización de accountability en los informes anuales del Tribunal de Cuentas de Santa Catarina

Este artículo presenta los resultados de la investigación que analizó la realización del potencial de accountability de los informes anuales (Pareceres Prévios - PP) producidos por el Tribunal de Cuentas del Estado de Santa Catarina (TCE/SC) relativo a las cuentas anuales de los jefes de los gobiernos municipales. La encuesta, teniendo como telón de fondo la necesidad de la análisis se desarrollar en dos dimensiones distintas y el debate sobre el modelo de análisis utilizado, mostró que los PPs realizan poco de su potencial de accountability, dado que el TCE/SC no avanza en relación a este objetivo, no usando o explorando las posibilidades que ofrece la legislación, y por lo tanto no contribuyendo a la materialización de la accountability. Por último, se sugiere algunas recomendaciones que podrían servir como directrices de investigación en el futuro.

Palabras clave: accountability; informes anuales; cuentas anuales; tribunal de cuentas; estado de Santa Catarina.

Artigo recebido em 10 ago. 2012 e aceito em 16 abr. 2013. 
The realization of accountability in preliminary reports of the Court of Auditors of Santa Catarina This article presents the results of research that aimed to analyze the realization of the accountability of preliminary reports (Pareceres Prévios - PP) produced by the Court of Auditors of the State of Santa Catarina (TCE/SC) concerning the annual accounts of Heads of municipal governments. Against the backdrop of the analysis need evidencing unfold in two distinct dimensions and the discussion of the analysis model used, the research showed that those PPs held little potential for accountability, given that the TCE/SC little advances in relation to this goal, not using or exploring the possibilities and the potential that the legislation offers and therefore do not contribute to the materialization of accountability. Finally, suggests some recommendations that could serve as guidelines in future research.

KEYWORDs: accountability; preliminary reports; annual accounts; court of accounts; state of Santa Catarina.

\section{Introdução}

Ao tempo em que os tribunais de contas (TCs) não podem se eximir de seguir rigorosamente a lei, é forçoso admitir que essa mesma lei lhes proporciona autonomia e independência para realizarem suas atribuições.

É o caso do Tribunal de Contas do Estado de Santa Catarina (TCE/SC), cujas competências para fiscalizar os municípios vão muito além da simples apreciação da gestão orçamentária, patrimonial e financeira, pois the compete, também, apreciar se as operações realizadas na execução dos orçamentos públicos municipais estão de acordo com as normas constitucionais, legais e regulamentares; avaliar o cumprimento dos programas previstos na Lei Orçamentária Anual (LOA) quanto à legalidade, legitimidade, economicidade, à consecução de objetivos e metas, bem como à sua consonância com o Plano Plurianual (PPA) e com a Lei de Diretrizes Orçamentárias (LDO); além de avaliar o reflexo da administração financeira e orçamentária municipal no desenvolvimento econômico e social dos municípios a ele jurisdicionados. $\mathrm{O}$ tribunal pode, ainda, por decisão do relator do processo, solicitar esclarecimentos adicionais e efetuar, por intermédio das unidades próprias, levantamentos necessários à elaboração do seu relatório.

Estas competências há muito foram asseguradas ao TCE/SC, não só na Constituição do Estado de Santa Catarina (Cesc/89), mas em sua Lei Orgânica e em seu Regimento Interno. Portanto, dadas não só as condições trazidas pela Constituição Federal de 1988 (CF/88), mas também constitucionais e legais constantes do ordenamento jurídico catarinense, o TCE/SC possui todo um aparato normativo que potencializa a realização da accountability em seus pareceres prévios, ainda que esse potencial não seja plenamente utilizado.

A pesquisa foi orientada por duas premissas: a) dadas as condições constitucionais e legais constantes do ordenamento jurídico brasileiro, os pareceres prévios são instrumentos de controle que possuem inegável potencial de accountability; e b) os TCs devem dar cumprimento ao princípio do "poder-dever", isto é, à obrigação de utilizar o poder do qual estão investidos para atingir as finalidades públicas que lhes são atribuídas (Meirelles, 2007). Daí 
estarem esses tribunais obrigados a utilizar suas atribuições e prerrogativas para informar e esclarecer todos os atos que envolvam a administração pública, de forma a permitir que a sociedade exerça o seu direito de controlar o governo.

A partir desse pano de fundo, fixou-se como objetivo geral analisar a realização do potencial de accountability dos pareceres prévios produzidos pelo Tribunal de Contas do Estado de Santa Catarina.

Importante observar que a legislação brasileira não se refere expressamente à accountability. Nem poderia fazê-lo, dado que este é um termo estrangeiro, não incorporado ao vocabulário nacional. A forma de verbalizar a accountability no Brasil é a expressão "prestação de contas". Guardadas as devidas proporções, principalmente quanto à amplitude e à abrangência definidas pelo uso e pela prática associada a cada uma dessas expressões, a mens legis brasileira, ao determinar a regular prestação de contas e o julgamento político das contas dos chefes de governo, busca, sem dúvida, torná-los accountable para a sociedade.

Por outro lado, não se pode deixar de considerar, também, o nível de complexidade dos estudos sobre accountability. Como alertam Denhardt e Denhardt (2007), este é um fenômeno complexo, pois as questões que envolvem a responsabilidade e a responsabilização no serviço público não são simples.

Assim, o texto está organizado em sete partes, a começar por esta introdução. A segunda parte trata dos fundamentos e da base teórica necessária à discussão das dimensões de análise da accountability e do modelo de análise adotado, o qual é apresentado na terceira parte. Na quarta parte são discutidos o método e os procedimentos adotados na pesquisa. $\mathrm{Na}$ quinta parte faz-se a caracterização do objeto da pesquisa: o parecer prévio. Os resultados da pesquisa e a discussão sobre a realização do potencial de accountability dos pareceres prévios produzidos pelo TCE/SC são o objeto da quinta parte. A sexta parte é dedicada à apresentação das conclusões e, na sétima, são apresentadas as referências bibliográficas.

Cabe observar, ainda, que a expressão accountability, mesmo quando usada de forma genérica, tem como referência a sua vertente horizontal (ou controle institucional), conforme a definem O'Donnell (1988a) e Mainwaring (2005), isto é, a que se manifesta no interior do aparato do Estado e é promovida pelos órgãos ou agências que têm atribuições e poder legal para tal.

Por fim, dois aspectos devem ser destacados. Primeiro, a partir da constatação de que os PPs são quase desconhecidos do público e pouco estudados no âmbito da academia (Speck, 2000), e ao se considerar que a investigação sobre a atuação das instituições políticas e suas práticas no sentido da ampliação da accountability é uma ferramenta importante para melhorar o desempenho do Estado e fundamental para aprimorar a democracia no país, inegável a relevância do tema e da abordagem proposta. O segundo é que, não obstante o fato de que os resultados da pesquisa não possam ser extrapolados para além do TCE/SC e dado que a accountability tem caráter progressivo e sua evolução depende das condições sociais e políticas de cada momento histórico, o que também limita os resultados da pesquisa ao seu universo temporal, o modelo aqui proposto pode ser utilizado como referencial para pesquisas semelhantes em outros TCs. 


\section{A accountability e a atuação dos tribunais de contas}

Nas democracias representativas modernas, como é o caso do Brasil, as atividades dos governantes devem estar circunscritas pelas leis e desenvolverem-se dentro dos limites dos interesses democráticos e sociais. Por isso, como afirma Arato (2002), já não é suficiente que os governos respondam exclusivamente aos corpos de representação popular, mas também aos próprios cidadãos, mesmo porque a única forma de obrigar os governantes a cumprirem as promessas pelas quais foram eleitos é exigir que eles expliquem o que fazem; é submetê-los à accountability.

Mas o que significa, efetivamente, accountability? Buscando uma compreensão melhor do conceito, Pinho e Sacramento (2009) empreenderam uma consulta aos dicionários de inglês para daí extrair um significado passível de tradução. Os autores concluíram que "não existe um termo único em português para expressar o termo accountability, havendo que trabalhar com uma forma composta", já que a "accountability encerra a responsabilidade, a obrigação e a responsabilização (...)" (Pinho e Sacramento, 2009:1348).

Se, no plano geral, a accountability se realiza no processo eleitoral, com o cidadão exercendo o seu poder de eleger seus governantes e representantes, ela também se realiza no plano específico da atuação dos agentes e das organizações públicas, não só a partir das diferentes instâncias de controle no interior da estrutura do Estado, mas, também, por intermédio do controle exercido pela imprensa, pelas organizações e associações da sociedade civil e pelos próprios cidadãos.

Esses dois planos da accountability foram originalmente propostos por O'Donnell (1998) na hoje clássica distinção em vertical e horizontal. No primeiro, ela é produto da ação política do cidadão e da sociedade e é exercida pelos atores sociais em relação aos atores estatais. No segundo, é exercida no interior do próprio Estado pelos diversos órgãos e agências estatais com poder para tal. Classificações semelhantes são apresentadas por Mainwaring (2005), que distingue a accountability em eleitoral e intraestatal, por Abrucio e Loureiro (2004), que a dividem em processo eleitoral e controle institucional durante o mandato, além de Kenney (2005), Smulovitz e Peruzzotti (2005), entre outros.

Importante destacar que o caráter de obrigação embutido no conceito de accountability é objetivo, isto é, determina a responsabilidade de uma pessoa perante outra. E se tal responsabilidade "não é sentida subjetivamente (da pessoa perante si mesma) pelo detentor da função pública, deverá ser exigida 'de fora para dentro'; deverá ser compelida pela possibilidade da atribuição de prêmios e castigos àquele que se reconhece como responsável" (Campos, 1990:3-4).

A accountability pode ser entendida, assim, como um processo de avaliação e responsabilização permanente dos agentes públicos pelo uso do poder que lhes é concedido pela sociedade, desde que esta responsabilização se dê mediante algum tipo de sanção, seja negativa (punição) ou positiva (prêmio), e tenha ela natureza legal ou moral (O’Donnell, 1998; Abrúcio e Loureiro, 2004; Mainwaring, 2005).

A importância da accountability se impõe na medida em que possibilita "meios democráticos de monitorar e controlar a conduta dos governantes, por prevenir concentrações de 
poder e por aumentar a capacidade de aprendizado e a efetividade da administração pública" (Bovens, 2006:25), mormente quando sabemos que o Brasil é uma "democracia delegativa", isto é, embora disponha dos instrumentos próprios das democracias plenas, utiliza-os de forma parcial, na medida da pouca cobrança da sociedade em relação aos seus representantes e governantes, pois os cidadãos, ao elegê-los, outorgam-lhes plenos poderes de representação sem, no entanto, exigir-lhes as necessárias prestações de contas, gerando um verdadeiro "déficit de accountability" (O’Donnell, 1998).

Sem entrar no mérito da discussão sobre a evolução política do país, importa destacar que a economia política no Brasil se estruturou a partir do patrimonialismo, herdado do período colonial, e que dá origem à burocracia e à corrupção que até hoje moldam a sociedade brasileira (Faoro, 2001). Também para Jaguaribe e colaboradores (1992), a cultura política brasileira é herdeira de grande influência e conserva diversas características de sua procedência ibérica, que marcam profundamente a cidadania e produzem extraordinária margem de diferenças culturais, sociais e econômicas entre pessoas e grupos que caracterizam a sociedade brasileira. Assim, não é difícil entender o "déficit de accountability" na sociedade brasileira, fato, aliás, realçado por Campos (1990) já no final da década de 1980, ao considerar como uma de suas causas o baixo estágio de desenvolvimento político e a consequente ausência de uma cidadania organizada no país. As democracias delegativas e os estados patrimonialistas "não só prescindem da accountability como a evitam" (Akutsu e Pinho, 2002:733).

Talvez por considerar essas questões, o legislador constituinte previu inúmeros instrumentos de accountability sobre o setor público e seus agentes, instituindo mecanismos de participação popular nas decisões públicas, determinando a regular prestação de contas de seus agentes e ampliando as competências, os poderes e a autonomia dos TCs - e, por consequência, sua participação nesse processo.

A CF/88 estabeleceu, por exemplo, a descentralização administrativa e tributária, o que resultou na delegação de poder participativo aos grupos organizados da sociedade local, com a instituição dos conselhos de políticas públicas nas áreas de planejamento, saúde e ensino (artigos 29, XI; 198, III; e 206, VI, respectivamente). Assegurou, também, a obrigatoriedade de disponibilização anual das contas públicas para o cidadão, permitindo-lhe avaliar e questionar o uso dos recursos (art. 31, § 3을 (Ipea, 2010).

A CF/88 estabeleceu, ainda, a obrigatoriedade da estruturação de sistemas de controle internos para os poderes nos três níveis de governo; a ampliação da autonomia, das atribuições e da autoridade do Tribunal de Contas da União (TCU) e do Ministério Público (MP); uma nova dinâmica de formulação e controle do orçamento, com a criação de novos instrumentos orçamentários: o Plano Plurianual (PPA) e a Lei de Diretrizes Orçamentárias (LDO); a obrigatoriedade da oitiva popular, mediante audiências públicas, principalmente nas fases de elaboração e discussão do processo orçamentário, mas também para outras tantas atividades públicas; a consolidação do componente técnico no julgamento político dos chefes de governo, em seus três níveis, mediante a obrigatoriedade da emissão de pareceres prévios pelos respectivos TCs e assim por diante. Além disso, também o legislador ordinário proporcionou 
um considerável reforço nessa luta ao aprovar a Lei Complementar $n^{\circ}$ 101, de 4 de maio de 2000, a Lei de Responsabilidade Fiscal (LRF).

No âmbito do controle institucional, os TCs receberam dos legisladores um aparato legal e instrumental que lhes permite amplas condições para promover a accountability. Tal aparato se consolida não só na sua independência, mas pelas amplas atribuições e competências exclusivas elencadas no art. 71 da CF/88 e, mais recentemente, pela LRF.

No Brasil, os TCs possuem características peculiares, uma vez que são órgãos híbridos, com funções de caráter técnico e jurisdicional, tendo como modelo o TCU. Ademais, se moldam em um modelo particular, pois possuem linha hierárquica própria e independente, não subordinada a qualquer dos poderes; gozam de autonomia administrativa e funcional; têm iniciativa legislativa própria e competência normativa e reguladora específica e seus membros possuem garantias constitucionais idênticas às dos magistrados, embora não componham o Poder Judiciário (Guerra, 2005; Andrada e Barroso, 2010).

Este aparato legal aproxima os TCs da própria essência da accountability, na medida em que possibilita sua atuação como verdadeiros instrumentos de controle social. Portanto, é natural - e necessário - que as informações e análises produzidas pelos TCs sejam amplas e completas. Mas, em geral, essa não parece ser a lógica, ao menos é a conclusão a que se pode chegar a partir da revisão dos estudos a respeito.

Em recente pesquisa, Arantes, Abrucio e Teixeira (2005) buscaram avaliar a imagem dos TCs estaduais. Nesse estudo, os autores destacam que esses órgãos têm avaliação geral positiva da sociedade quanto às suas capacidades administrativas, o que lhes garantiria condições básicas para exercer bem suas funções de controle, enquanto as principais críticas à atuação desses tribunais se dirigem ao mérito de suas decisões. Além dos requisitos do controle meramente formal, há um anseio de que esses tribunais se concentrem na avaliação do alcance das políticas governamentais.

Outros trabalhos, a exemplo de Barros (2000), Rocha (2009), Loureiro, Teixeira e Moraes (2009) e Kronbauer e colaboradores (2011), reforçam e ampliam a percepção de que, em sua grande maioria, os TCs brasileiros não se aproximam da substância da accountability, já que as informações produzidas por esses órgãos não atendem aos anseios e necessidades da sociedade, restringindo-se à verificação da conformidade da ação dos agentes públicos, sem expandir seus horizontes para além dessa visão limitada.

\subsection{As dimensões de análise da accountability e os pareceres prévios}

Ao discorrer sobre o significado de democracia, Bobbio (2007) alerta que, além de ver a democracia como forma de governo, a linguagem política moderna a vê também como um conjunto de valores. Com isso, "(...) foi introduzida a distinção entre democracia formal, que diz respeito precisamente à forma de governo, e democracia substancial, que diz respeito ao conteúdo dessa forma" (Bobbio, 2007:157). 
Esta distinção entre forma e conteúdo, ou seja, entre a forma e a substância contida na forma, serve como ponto de referência para caracterizar as dimensões da accountability. A forma pode ser consubstanciada na obrigação do Estado em fiscalizar (e punir, quando necessário) seus próprios agentes, porém, agindo na forma e nos exatos limites da lei; a substância, na importância e no conteúdo daquilo que se procura e que se revela dessa fiscalização. Caracterizam-se, assim, duas dimensões desse processo: a dimensão formal e a dimensão substantiva. A primeira, envolvendo a forma pela qual o processo é conduzido; a segunda, o que é importante extrair desse processo.

É imperioso admitir que a accountability, como processo, se subordina à lei e está subjugada ao estado de direito, definido este como o Estado juridicamente organizado e obediente às suas próprias leis (Meirelles, 2007). Esta percepção leva à constatação de que, qualquer que seja o aparato utilizado pelo Estado para promover a accountability, é necessário que tal aparato se enquadre nos processos legais. Não se pode esquecer que fiscal e fiscalizado são agentes públicos e integram o próprio Estado, subordinando-se, em consequência, às estritas determinações da lei.

Portanto, já aqui, é possível apontar uma questão fundamental para caracterizar as dimensões que devem ser levadas em conta numa análise da accountability: o necessário enquadramento de seu processo formal aos limites da lei.

Também Schedler (1999:14) distingue dois sentidos que o termo accountability suscita: a) a obrigação dos agentes de informar ao público sobre suas atividades e justificarem-nas (answerability); e b) a capacidade das agências de controle de fazer cumprir a lei e aplicar sanções aos que violaram determinadas regras de conduta (enforcement).

Partindo da premissa de que a accountability subsiste a partir da existência do poder e da necessidade de que ele seja controlado, o autor apresenta uma concepção radial, identificando três formas básicas para prevenir do abuso do poder: a) obrigar que seu exercício se dê de forma transparente (informação); b) forçar que os agentes públicos justifiquem seus atos (justificação); e c) sujeitar o detentor do poder a sanções (punição). Estes três elementos — informação, justificação, punição — são, portanto, caracterizadores do conceito de accountability (Schedler, 1999:14).

Observando-se esta caracterização sob uma ótica mais específica, é possível extrair daí um conjunto de valores que dizem respeito tanto à forma quanto à substância da $a c$ countability. A obrigação de informar engloba dois tipos de questões: a primeira, relativa ao direito dos cidadãos de receberem informações sobre as decisões tomadas pelos governantes; a segunda, relativa à necessidade dos governantes de explicar suas decisões. Neste sentido, a obrigação de informar (answerability) é uma obrigação do governante: de responder (atender) às necessidades e interesses da sociedade, informando e justificando suas atividades, mas também cumprindo a lei e submetendo-se a sanções se não o fizer. Trata-se, aqui, da substância da ação de governar: atender às necessidades e interesses da sociedade e cumprir a lei. 
A capacidade de fazer cumprir a lei e aplicar sanções (enforcement), por outro lado, envolve outro grupo de atores: os órgãos e agentes que detêm a atribuição legal e a capacidade institucional para tal. Neste caso, não se trata da obrigação do governante, mas da atribuição do fiscal de fiscalizar e punir de acordo com a lei. Trata-se, portanto, da forma, isto é, dos limites e dos procedimentos impostos pela lei ao fiscal, que lhe impedem o arbítrio, a prepotência e o abuso de poder e garantem os direitos dos fiscalizados, como institutos fundamentais do estado de direito e pilares da democracia.

A proposta de Schedler (1999) reforça a necessidade de analisar a accountability por dois ângulos distintos: o da "obrigação" do agente público de agir e prestar contas (answerability) e o da "obrigação" do agente fiscalizador de fazer cumprir a lei e aplicar sanções (enforcement).

Esta concepção também ajuda a entender e a delimitar com mais clareza as duas dimensões - a formal e a substantiva — necessárias à análise do processo de accountability. Em primeiro lugar, deve-se verificar se o agente fiscalizador cumpre a lei e se age nos estritos limites dos procedimentos legais. Trata-se, portanto, de verificar se os aspectos formais que envolvem obrigatoriamente o processo de accountability são atendidos. É a sua dimensão formal. Em segundo lugar, deve-se focar o conteúdo daquilo que se fiscaliza, isto é, verificar como e de que forma o agente público vem realizando suas atividades e como tem respondido (atendido) às necessidades e interesses da sociedade. Esta é a dimensão substantiva da accountability.

\section{Modelo de análise}

O modelo de análise é mostrado no quadro a seguir.

Quadro 1

Modelo de análise

\begin{tabular}{|c|c|c|c|}
\hline $\begin{array}{l}\text { Dimensões da } \\
\text { Accountability }\end{array}$ & $\begin{array}{l}\text { Componentes } \\
\text { (temas) }\end{array}$ & $\begin{array}{l}\text { Indicadores } \\
\text { (conceitos-chave) }\end{array}$ & $\begin{array}{l}\text { Definição dos indicadores } \\
\text { (unidades de significação) }\end{array}$ \\
\hline \multirow{5}{*}{$\begin{array}{l}\text { Dimensão } \\
\text { Formal da } \\
\text { Accountability }\end{array}$} & \multirow{2}{*}{ Publicidade } & Disponibilidade & $\begin{array}{l}\text { atendimento à determinação legal de "ser público"; de estar à } \\
\text { disposição do público; }\end{array}$ \\
\hline & & Divulgação & $\begin{array}{l}\text { publicação dos pareceres prévios em mídia de amplo acesso } \\
\text { e/ou circulação; }\end{array}$ \\
\hline & \multirow{2}{*}{ Justificação } & Ampla defesa & $\begin{array}{l}\text { oportunidade dada ao prefeito de apresentar explicações e } \\
\text { justificativas antes da emissão da decisão pelo tribunal, mediante } \\
\text { o conhecimento do inteiro teor do Repp; }\end{array}$ \\
\hline & & Contraditório & $\begin{array}{l}\text { registro e análise das explicações e justificativas apresentadas } \\
\text { pelo prefeito, bem como da contra-argumentação e das } \\
\text { conclusões apontadas pelo tribunal; }\end{array}$ \\
\hline & Sanção & Decisão & $\begin{array}{l}\text { ato declaratório formal prolatado pelo plenário do tribunal, } \\
\text { vinculado ao Repp, propondo a aprovação ou rejeição das } \\
\text { contas anuais; }\end{array}$ \\
\hline
\end{tabular}




\begin{tabular}{|c|c|c|c|}
\hline $\begin{array}{l}\text { Dimensões da } \\
\text { Accountability }\end{array}$ & $\begin{array}{l}\text { Componentes } \\
\text { (temas) }\end{array}$ & $\begin{array}{l}\text { Indicadores } \\
\text { (conceitos-chave) }\end{array}$ & $\begin{array}{l}\text { Definição dos indicadores } \\
\text { (unidades de significação) }\end{array}$ \\
\hline \multirow{9}{*}{$\begin{array}{l}\text { Dimensão } \\
\text { Substantiva da } \\
\text { Accountability }\end{array}$} & \multirow[t]{2}{*}{ Conformação } & Conformidade & $\begin{array}{l}\text { verificação do cumprimento das normas, regulamentos e } \\
\text { procedimentos administrativos na prática dos atos de gestão e } \\
\text { das ações de governo; }\end{array}$ \\
\hline & & Legalidade & $\begin{array}{l}\text { verificação do cumprimento das determinações legais na prática } \\
\text { dos atos de gestão e das ações de governo; }\end{array}$ \\
\hline & \multirow{3}{*}{ Desempenho } & Eficiência & $\begin{array}{l}\text { análise/avaliação da relação custo-benefício na prática dos atos } \\
\text { de gestão e das ações de governo; }\end{array}$ \\
\hline & & Eficácia & $\begin{array}{l}\text { análise/avaliação da consecução de objetivos e metas na prática } \\
\text { dos atos de gestão e das ações de governo; }\end{array}$ \\
\hline & & Efetividade & $\begin{array}{l}\text { análise/avaliação dos efeitos e impactos advindos da prática dos } \\
\text { atos de gestão e das ações de governo; }\end{array}$ \\
\hline & Atuação Ética & Imputação & $\begin{array}{l}\text { divulgação sistemática e sistematizada das sanções imputadas } \\
\text { aos administradores, advindas do conjunto dos procedimentos } \\
\text { de fiscalização realizados no município; }\end{array}$ \\
\hline & $\begin{array}{l}\text { Compromisso } \\
\text { com os } \\
\text { Princípios } \\
\text { Democráticos }\end{array}$ & Participação & $\begin{array}{l}\text { análise/avaliação das circunstâncias e resultados da participação } \\
\text { da população na distribuição e destinação dos recursos públicos, } \\
\text { quando da realização de audiências públicas, assembleias etc., } \\
\text { em cumprimento às determinações legais; }\end{array}$ \\
\hline & \multirow{2}{*}{$\begin{array}{l}\text { Defesa do } \\
\text { Interesse Público }\end{array}$} & Responsividade & $\begin{array}{l}\text { análise/avaliação sobre a vinculação entre a execução } \\
\text { orçamentária e os objetivos e metas constantes do PPA } \\
\text { aprovado pelo município; }\end{array}$ \\
\hline & & Transparência & $\begin{array}{l}\text { análise/avaliação sobre a vinculação entre a execução } \\
\text { orçamentária e as funções de governo afetas ao município, } \\
\text { conforme planejado no orçamento aprovado. }\end{array}$ \\
\hline
\end{tabular}

Fonte: Elaboração do autor.

A concepção do modelo de análise teve por base os trabalhos de Bobbio (2007), Dahl (1997), Denhardt e Denhardt (2007), Kaldor (2003), Kenney (2005), Koppell (2005), Mainwaring (2005), Meirelles (2007), O’Donnell (1998) e Schedler (1999), a partir dos quais foram estabelecidas as duas dimensões da accountability (Rocha, 2009), bem assim os seus componentes e indicadores.

Os componentes que integram a dimensão formal da accountability são a publicidade, a justificação e a sanção. Em relação à dimensão substantiva, seus componentes são a conformação, o desempenho, a atuação ética, a defesa dos princípios democráticos e o interesse público.

É importante ressaltar que, em alguns casos, pode ocorrer que um indicador se faça presente no Repp analisado, demonstrando que determinado tema foi abordado, mas que sua abordagem tenha sido uma referência incidental, isto é, se tenha apresentado de forma eventual e não sistematizada. Por essa razão, nestes casos, objetivando manter o rigor dos resultados da pesquisa, optou-se pela apresentação desse indicador separado do indicador principal, denominando-o de "indicador incidental". 


\section{Método e procedimentos}

A presente pesquisa caracteriza-se como exploratória e descritiva, com uma abordagem qualitativa, e constituiu-se na forma de pesquisa documental, com a utilização das técnicas da análise de conteúdo (Bardin, 2009; Richardson et al., 1999).

A pesquisa teve como objeto os pareceres prévios emitidos pelo Tribunal de Contas do Estado de Santa Catarina, relativos às contas do biênio 2008-09 dos chefes dos executivos municipais do estado.

Neste sentido, considerando-se os documentos constituintes do objeto da pesquisa, adotou-se, para efeitos deste estudo, a seguinte nomenclatura:

a) Prestação de Contas Anuais (PCA): todo o conjunto de documentos que compõem o processo de prestação das contas que os prefeitos submetem anualmente ao tribunal; e

b) Parecer Prévio (PP): conjunto de documentos composto pelo "Relatório para Emissão de Parecer Prévio (Repp)" e pela decisão proferida pelo plenário do tribunal.

Assim, o corpus submetido aos procedimentos analíticos é composto pelo Repp e pela decisão, tendo em vista que esses documentos constituem, de fato, o que aqui se denomina genericamente de parecer prévio.

Os procedimentos adotados foram, em resumo, os seguintes:

a) identificação das dimensões da accountability presentes nos PPs, verificando se cada um deles apresenta os componentes que permitem conferir se a dimensão formal e a substantiva da accountability estão neles presentes;

b) caracterização de cada um dos PPs objeto de análise, segundo as dimensões da accountability neles identificadas, mediante a verificação e a explicitação da ocorrência ou não dos indicadores/componentes das dimensões da accountability;

c) avaliação da realização do potencial de accountability nos PPs, pela constatação da presença e da ausência dos diferentes indicadores/componentes em cada um deles; e

d) evidenciação da realização do potencial de accountability dos PPs, explorando as possibilidades contidas no conjunto dos Repps analisados.

\subsection{Caracterização do parecer prévio}

A caracterização de cada PP se dá pela constatação da presença ou não dos componentes e indicadores das dimensões da accountability.

A presença de todos os indicadores que consubstanciam os componentes de uma dimensão da accountability, independentemente da sua frequência, caracteriza a condição de atendimento pleno do PP em relação àquela dimensão. 
A ausência de um ou mais indicadores de uma mesma dimensão no PP poderá caracterizar tanto a condição de atendimento parcial, quanto a condição de não atendimento. A hipótese, no primeiro caso, é que a ausência do indicador não configure a ausência do componente. Se a ausência do componente se configurar, afigura-se a segunda hipótese.

O quadro a seguir apresenta a escala de caracterização do parecer prévio.

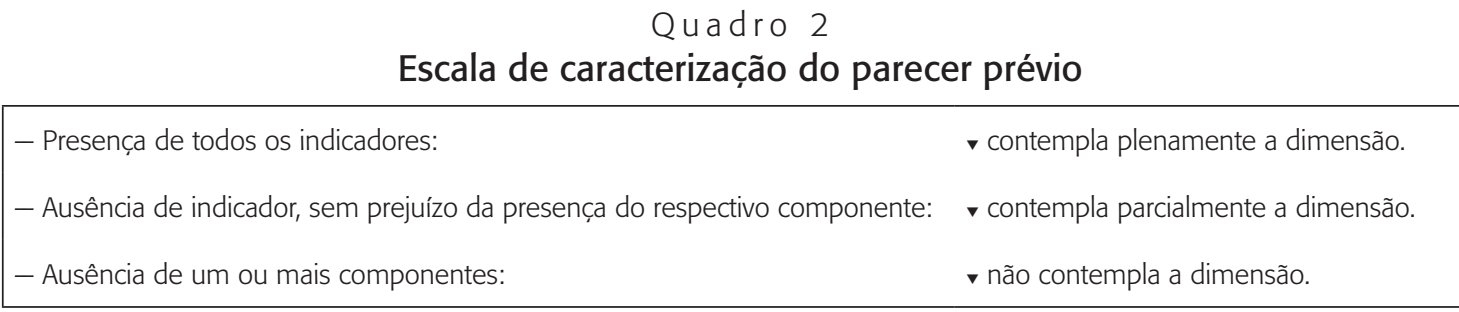

Fonte: Elaboração do autor.

\subsection{A realização do potencial dos pareceres prévios}

Tomando-se as duas extremidades da classificação, se os pareceres prévios pesquisados apresentam todos os componentes que caracterizam a ambas as dimensões da accountability, significa que realizam plenamente seu potencial de accountability. Se, ao invés, deixam de apresentar algum desses componentes, significa que não realizam o seu potencial de accountability.

O quadro a seguir apresenta a escala de potencialidade dos pareceres prévios.

$$
\text { Quadro } 3
$$

\section{Escala de potencialidade dos pareceres prévios}

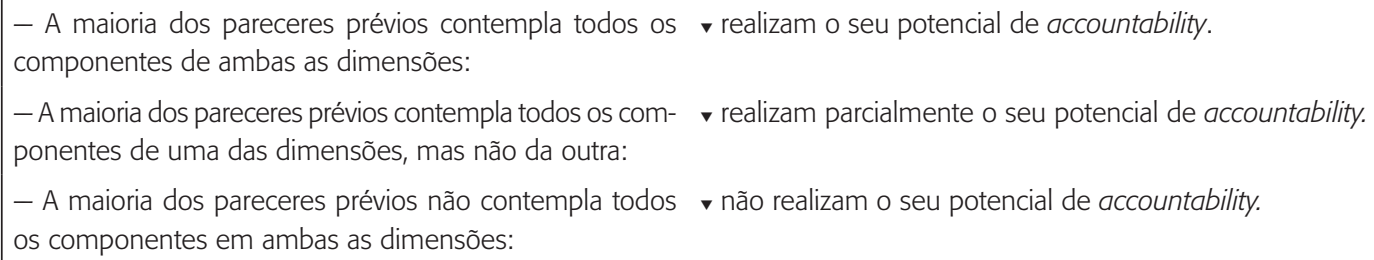

Fonte: Elaboração do autor.

Assim, no primeiro caso, os pareceres prévios podem ser considerados instrumentos plenos de accountability, pois realizam seu potencial como tal, enquanto, no segundo, não podem ser considerados instrumentos de accountability na medida em que não o realizam. 


\section{Realização do potencial de accountability dos pareceres prévios do TCE/SC}

Conforme mostrado nos quadros a seguir, os seis municípios componentes da amostra, cujos Repps foram considerados para efeitos da pesquisa, deram origem a 133 Unidades de Contexto, a partir das quais foram identificadas e analisadas 279 Unidades de Registro.

$$
\text { Quadro } 4
$$

Municípios componentes da amostra da pesquisa (em ordem alfabética e ano do PP) e no do Repp

\begin{tabular}{|ll|}
\hline Município & Número do Repp \\
Concórdia, 2009 & $2993 / 2010$ - Relatório de Instrução \\
Florianópolis, 2008 & $5034 / 2009$ - Relatório de Reinstrução \\
Itaiópolis, 2009 & $4076 / 2010$ - Relatório de Reinstrução \\
Lages, 2008 & $3520 / 2009$ - Relatório de Instrução \\
Rio do Sul, 2009 & $3345 / 2010$ - Relatório de Instrução \\
São Miguel da Boa Vista, 2009 & $4071 / 2010$ - Relatório de Reinstrução \\
\hline
\end{tabular}

Fonte: Elaboração do autor.

Quadro 5

Quantitativo de Unidades de Contexto e Unidades de Registro analisadas

\begin{tabular}{|lcc|}
\hline Pareceres Prévios & Unidades de Contexto & Unidades de Registro \\
Concórdia & 20 & 42 \\
Florianópolis & 21 & 52 \\
Itaiópolis & 23 & 47 \\
Lages & 27 & 52 \\
Rio do Sul & 20 & 43 \\
São Miguel da Boa Vista & 22 & 43 \\
Totais & 133 & 279 \\
\hline
\end{tabular}

Fonte: Elaboração do autor.

Importa assinalar que o TCE/SC segue um rígido padrão para a composição e elaboração dos seus Repps, determinando estruturas perfeitamente idênticas, apenas com dados diferentes. Com isso, de início verificou-se a perfeita homogeneidade dos relatórios, o que tornou desnecessário constituir-se uma amostra probabilística, haja vista que cada um dos elementos que compõem o universo da pesquisa pode ser tomado como sujeito-tipo, isto é, 
todos apresentam as características típicas dos integrantes da população (Richardson, 1999). Por essa razão, optou-se por uma amostra reduzida, não só por economia de tempo e recursos, mas, principalmente, porque prosseguir na análise dos demais municípios significaria uma contínua e sistemática repetição das análises anteriores.

Da análise empreendida nos pareceres prévios com o objetivo de caracterizá-los segundo a dimensão formal da accountability, verificou-se que somente três contemplam de forma parcial essa dimensão.

O quadro a seguir mostra a presença dos componentes/indicadores da dimensão formal nos PPs analisados.

Quadro 6

Presença dos componentes/indicadores da dimensão formal nos PPs analisados

\begin{tabular}{|c|c|c|c|c|c|}
\hline \multirow{3}{*}{ Pareceres Prévios } & \multicolumn{5}{|c|}{ Componentes/Indicadores } \\
\hline & \multicolumn{2}{|c|}{ Publicidade } & \multicolumn{2}{|c|}{ Justificação } & \multirow{2}{*}{$\begin{array}{l}\text { Sanção } \\
\text { Decisão }\end{array}$} \\
\hline & Disponibilidade & Divulgação & Ampla defesa & Contraditório & \\
\hline Concórdia & Presente & Ausente & Ausente & Ausente & Presente \\
\hline Florianópolis & Presente & Ausente & Parcial & Parcial & Presente \\
\hline Itaiópolis & Presente & Ausente & Parcial & Parcial & Presente \\
\hline Lages & Presente & Ausente & Ausente & Ausente & Presente \\
\hline Rio do Sul & Presente & Ausente & Ausente & Ausente & Presente \\
\hline S. Miguel da Boa Vista & Presente & Ausente & Parcial & Parcial & Presente \\
\hline
\end{tabular}

Fonte: Elaboração do autor.

A ausência de divulgação dos Repps em mídia de amplo acesso e/ou circulação é o primeiro óbice ao atendimento pleno da dimensão. Dos Repps analisados, nenhum havia sido publicado, ainda que todos atendessem à determinação legal de "ser público", isto é, de estar à disposição do público.

Embora o Repp seja um documento público e possa ser consultado por qualquer cidadão, este, para fazê-lo, deve dirigir-se à sede do TCE/SC ou à câmara de vereadores, locais em que estão disponíveis cópias do relatório impresso. Ele não está disponível por qualquer outra forma impressa ou em meio eletrônico. Somente a Decisão é publicada no Diário Oficial Eletrônico do Tribunal de Contas de Santa Catarina (DOTC-e).

Por outro lado, é necessário frisar que, mesmo não publicando o Repp, o tribunal cumpre a legislação pertinente, a qual apenas determina que "as contas do Município ficarão, durante sessenta dias, anualmente, à disposição de qualquer contribuinte, para exame e apreciação, o qual poderá questionar-lhes a legitimidade, nos termos da lei" (art. 113, § 4 da Cesc/89).

O segundo óbice ao atendimento pleno da dimensão dá-se em relação à ampla defesa e ao contraditório. Verifica-se, em três dos seis PPs analisados, que o tribunal não aponta res- 
trições que possam levar à rejeição das contas e, portanto, não é efetuada a oitiva do prefeito para a apresentação de explicações e justificativas relativas às demais restrições consignadas no relatório.

O quadro a seguir mostra a caracterização dos PPs como instrumentos de accountability quanto à dimensão formal.

Quadro 7

Caracterização dos PPs como instrumentos de accountability quanto à dimensão formal

\begin{tabular}{|ll|}
\hline Parecer prévio/ano & Caracterização como instrumento de accountability \\
\hline Concórdia, 2009 & Não contempla a dimensão \\
Florianópolis, 2008 & Contempla parcialmente a dimensão \\
Itaiópolis, 2009 & Contempla parcialmente a dimensão \\
Lages, 2008 & Não contempla a dimensão \\
Rio do Sul, 2009 & Não contempla a dimensão \\
São Miguel da Boa Vista, 2009 & Contempla parcialmente a dimensão \\
\hline
\end{tabular}

Fonte: Elaboração do autor.

Da análise do conjunto dos PPs, pode-se concluir que metade deles não realiza o seu potencial de accountability, enquanto a outra metade o faz devido, principalmente, ao fato de que, nas contas dos municípios de Florianópolis, Itaiópolis e São Miguel da Boa Vista, o componente "justificação" da dimensão formal foi considerado contemplado, ainda que parcialmente, em razão da oitiva parcial dos respectivos prefeitos.

Em vista desse resultado, a dúvida que surge é saber como se comportou o tribunal em relação à oitiva do conjunto dos prefeitos que prestaram contas nesses dois exercícios, de forma a se estabelecer uma caracterização mais consistente dos PPs quanto à dimensão formal.

A partir dos dados estatísticos veiculados pelo próprio TCE/SC, em seu sítio na internet, verifica-se que, do total das 293 contas apresentadas em 2008, 148 foram objeto de oitiva dos prefeitos por parte do tribunal (TCE/SC, 2009:67). Já em 2009, o total de prefeitos ouvidos reduziu-se para 105 (TCE/SC, 2010:12).

Considerando-se que todos os municípios catarinenses apresentaram contas nesses dois anos, o percentual de prefeitos ouvidos em razão de restrições apontadas nos respectivos Repps foi de 50,5\% em 2008 e de 35,8\% em 2009. Portanto, do conjunto de 586 contas apresentadas em 2008 e 2009, somente em 253 foi efetuada a oitiva do prefeito, o que significa que os PPs, em seu conjunto, não contemplam a dimensão formal da accountability. Ou seja, somente considerando a dimensão formal, apenas 43,2\% dos PPs realizam o seu potencial de accountability e, ainda assim, de forma parcial.

O quadro a seguir mostra os dados relativos à oitiva dos prefeitos em relação aos processos de contas dos anos de 2008 e 2009. 
Quadro 8

Oitiva dos prefeitos em relação ao total de contas apresentadas em 2008 e 2009

\begin{tabular}{|lccc|}
\hline Contas municipais & Total de contas & Oitiva pré-decisão & Percentual \\
\hline Exercício de 2008 & 293 & 148 & 50,5 \\
Exercício de 2009 & 293 & 105 & 35,8 \\
Totais/média & 586 & 253 & 43,2 \\
\hline
\end{tabular}

Fonte: TCE/SC. Disponível em: <www.tce.sc.gov.br/files/file/publicacoes/controle_publico>.

Por fim, deve-se ressaltar, em relação a esta questão, que o aspecto legal relativo à ampla defesa e ao contraditório é atendido pelo tribunal. Nos termos do art. 55 da Lei Orgânica do TCE/SC, uma vez apreciadas as contas, o responsável tem até 15 dias, contados da publicação da respectiva decisão no Diário Oficial, para requerer a reapreciação das suas contas. Além disso, também a câmara de vereadores pode solicitar a reapreciação, sendo-lhe concedido um prazo de 90 dias, contados do recebimento do processo com a decisão do TCE/SC.

No que tange à análise com o objetivo de caracterizar os pareceres prévios segundo a dimensão substantiva da accountability, o panorama se agrava, pois nenhum deles contempla plenamente a dimensão.

O quadro abaixo mostra a incidência dos indicadores da dimensão substantiva.

Quadro 9

Incidência dos indicadores da dimensão substantiva nos PPs analisados

\begin{tabular}{|c|c|c|c|c|c|c|c|c|c|c|}
\hline \multirow{3}{*}{ Pareceres Prévios } & \multicolumn{10}{|c|}{ Incidência dos indicadores } \\
\hline & \multicolumn{2}{|c|}{ Conformidade } & \multicolumn{2}{|c|}{ Legalidade } & \multicolumn{2}{|c|}{ Imputação } & \multicolumn{2}{|c|}{ Responsividade } & \multicolumn{2}{|c|}{ Transparência } \\
\hline & Total & $\%$ & Total & $\%$ & Total & $\%$ & Total & $\%$ & Total & $\%$ \\
\hline Concórdia & 23 & 54,8 & 19 & 45,2 & - & - & - & - & - & - \\
\hline Florianópolis & 30 & 57,7 & 22 & 42,3 & 02 & 3,8 & 01 & 1,9 & - & - \\
\hline Itaiópolis & 28 & 59,6 & 19 & 40,4 & - & - & - & - & - & - \\
\hline Lages & 29 & 55,8 & 23 & 44,2 & - & - & - & - & - & - \\
\hline Rio do Sul & 24 & 55,8 & 19 & 44,2 & - & - & - & - & - & - \\
\hline S. Miguel da Boa Vista & 24 & 55,8 & 19 & 44,2 & - & - & - & - & 01 & 2,3 \\
\hline Total/Média & 158 & 56,6 & 121 & 43,4 & 02 & 0,7 & 01 & 0,4 & 01 & 0,4 \\
\hline
\end{tabular}

Fonte: Elaboração do autor.

Como se pode verificar, os PPs analisados praticamente só contemplam o componente "conformação", integrado pelos indicadores de "conformidade" e "legalidade", o que é revelador do extremo formalismo de que se reveste o trabalho do TCE/SC. 
Do total de 279 Unidades de Registro analisadas, 158 relacionam-se à conformidade; outras 121 referem-se à legalidade, e apenas quatro referem-se aos sete outros indicadores atinentes à dimensão substantiva da accountability, dois à "imputação", um à "responsividade" e um à "transparência". Mesmo assim, de forma incidental.

O quadro a seguir mostra a caracterização dos PPs como instrumentos de accountability quanto à dimensão substantiva.

Quadro 10

\section{Caracterização dos PPs como instrumentos de accountability quanto à dimensão substantiva}

\begin{tabular}{|ll|}
\hline Parecer Prévio/ano & Caracterização como instrumento de accountability \\
\hline Concórdia, 2009 & Não contempla a dimensão \\
Florianópolis, 2008 & Não contempla a dimensão \\
Itaiópolis, 2009 & Não contempla a dimensão \\
Lages, 2008 & Não contempla a dimensão \\
Rio do Sul, 2009 & Não contempla a dimensão \\
São Miguel da Boa Vista, 2009 & Não contempla a dimensão \\
\hline
\end{tabular}

Fonte: Elaboração do autor.

Da análise do conjunto dos PPs no que diz respeito à sua caracterização como instrumentos de accountability, consideradas a dimensão formal e a dimensão substantiva, tem-se:

$$
\text { Quadro } 11
$$

Caracterização dos PPs como instrumentos de accountability

\begin{tabular}{|llll|}
\hline Parecer Prévio/ano & $\begin{array}{c}\text { Quanto à dimensão } \\
\text { formal }\end{array}$ & $\begin{array}{c}\text { Quanto à dimensão } \\
\text { substantiva }\end{array}$ & \multicolumn{1}{c|}{$\begin{array}{c}\text { Como instrumento de } \\
\text { accountability }\end{array}$} \\
\hline Concórdia, 2009 & Não contempla & Não contempla & Não realiza seu potencial \\
Florianópolis, 2008 & Contempla parcialmente & Não contempla & $\begin{array}{l}\text { Realiza seu potencial } \\
\text { parcialmente }\end{array}$ \\
Itaiópolis, 2009 & Não contempla & Não contempla & $\begin{array}{l}\text { Realiza seu potencial } \\
\text { parcialmente }\end{array}$ \\
Lages, 2008 & Não contempla & Não contempla & Não realiza seu potencial \\
Rio do Sul, 2009 & Não contempla & Não realiza seu potencial \\
São Miguel da Boa Vista, 2009 & Contempla parcialmente & Não contempla & Realiza seu potencial \\
\hline
\end{tabular}

Fonte: Elaboração do autor. 
Por isso e diante das análises a que foram submetidos os PPs, é possível responder à questão: "como se realiza o potencial de accountability dos pareceres prévios do Tribunal de Contas do Estado de Santa Catarina?"

\section{Conclusões}

Os Pareceres Prévios produzidos pelos TCE/SC não realizam seu potencial de accountability, haja vista que:

— verifica-se a ausência de componentes em ambas as dimensões da accountability; e

- os indicadores que apontam algum potencial quanto à dimensão substantiva não apresentam relevância estatística.

Confirma-se, assim, o segundo pressuposto da pesquisa, de que os pareceres prévios não exploram os limites da lei, não aproveitando todas as possibilidades que esta lhes oferece para realizarem o seu potencial de accountability, não atendendo à sua dimensão substantiva.

Além dessa confirmação, evidenciou-se que o primeiro pressuposto não se mostrou verdadeiro, dado que os PPs também não atendem à dimensão formal da accountability.

A "conclusão" é que os pareceres prévios produzidos pelo TCE/SC pouco avançam em relação à accountability; não utilizam nem exploram as possibilidades e o potencial que a legislação lhes coloca à disposição; não contribuem mais amplamente no julgamento político dos chefes de governos municipais, além de também não contribuírem para a materialização da accountability, o que torna ainda mais difícil a consolidação de uma expressão em português que exprima toda a sua significação, além de dificultarem a consolidação da expressão "prestação de contas" para significar tudo o que se conceitua com accountability.

Sem dúvida, ao menos no âmbito estadual, a expressão "prestação de contas" poderia se aproximar muito mais do conceito de accountability não fosse a pouca "ousadia" do TCE/SC em seus pareceres prévios, cingido que está pelos aspectos mais formais do controle.

Cabe observar que a ampliação da produção de informações, de análises e de avaliações por parte do TCE/SC, por outro lado, não passa por quaisquer impedimentos de ordem legal, bastando, para viabilizar essa ampliação, vontade e disposição do tribunal. Nesse sentido, chama especial atenção o art. 84 do seu Regimento Interno, que prevê o conteúdo do relatório do Controle Interno que deve acompanhar as contas do governo municipal (TCE/SC, 2002). Uma simples regulamentação desse artigo - promovendo um maior detalhamento da forma e especificando que informações e análises tais relatórios deveriam conter — seria suficiente para possibilitar um incremento de qualidade nos Repps.

Ademais, com tal providência, além de reforçar a importância da atuação do controle interno no âmbito de cada município, promove-se um maior comprometimento da própria administração municipal com o processo de prestação de contas anuais.

Ao se focar as conclusões propiciadas pela pesquisa quanto aos aspectos da dimensão formal da accountability, algumas questões são evidenciadas e merecem reflexão. 
A primeira questão que se impõe é por que o TCE/SC não publica e/ou disponibiliza em meio eletrônico os seus Repps, embora, aparentemente, não haja justificativa para essa omissão. Como ficou evidente na pesquisa, o acesso aos Repps só é possível mediante a consulta a cópias do relatório impresso na sede do tribunal ou na câmara de vereadores.

Por outro lado, desde o início da década de 2000, os Repps são produzidos em meio eletrônico e, portanto, para sua ampla divulgação bastaria deixá-los à disposição no próprio sítio do TCE/SC. Dessa forma, ainda que se possa discutir se o sítio do TCE/SC pode ser considerado mídia de amplo acesso e/ou circulação, as eventuais questões envolvendo os custos de publicação seriam superadas.

Outra questão evidenciada na pesquisa, relativa à dimensão formal da accountability, é a inexistência de explicações e justificativas dos prefeitos em relação a todas as restrições apontadas no Repp.

Trata-se, no caso, de garantir ao cidadão e à sociedade o direito fundamental de obter explicações sobre os atos e ações de seus governantes, e, paralelamente, permitir que estes se defendam de eventuais imputações, quaisquer que sejam. Ao não ouvir os prefeitos e ao não oportunizar previamente a ampla apresentação de explicações e justificativas, o TCE/SC não só desestimula a manifestação desses responsáveis, como impede uma discussão mais abrangente e transparente sobre a gestão pública, deixando de produzir e divulgar informações que, além de eventualmente explicarem determinadas atitudes e ações dos administradores, permitiriam um maior nível de transparência e propiciariam mais elementos ao Legislativo e à sociedade para formar um juízo de valor mais apropriado e aprofundado sobre a atuação de seus governantes.

Deve-se considerar, no entanto, que o aspecto estritamente legal é atendido pelo tribunal, dado que o responsável tem até 15 dias, contados da publicação da respectiva Decisão no Diário Oficial, para requerer a reapreciação de suas contas. Essa prerrogativa a posteriori, todavia, não contempla o que é fundamental para a accountability; a informação. Parece pouco provável que algum prefeito se proponha a promover a reapreciação das suas contas para discutir, explicar e justificar seus atos e decisões quando estas já tenham sido objeto de proposta de aprovação pelo tribunal.

Quando se foca a dimensão substantiva, as questões evidenciadas pela pesquisa se avolumam e revelam o formalismo de que se reveste o trabalho do TCE/SC.

O tribunal, ao produzir os seus PPs, praticamente só trata da conformidade e da legalidade da ação administrativa, e apenas incidentalmente aborda outras questões atinentes à dimensão substantiva da accountability; mesmo assim, sem método nem sistematização.

Ficou evidente, pelos resultados obtidos, a ausência de avaliações quanto ao desempenho dos governos. E não é porque o TCE/SC não disponha de um mínimo de informações a esse respeito, pois o tribunal promove regularmente fiscalizações e auditorias nas prefeituras.

A este respeito, aliás, merece atenção o tratamento dado às auditorias. É o próprio tribunal que afirma textualmente nas considerações ("considerandos") de seus Repps que o exame das contas dos municípios para efeito da emissão dos respectivos pareceres prévios 
"não envolve o resultado de eventuais auditorias oriundas de denúncias, representações e outras, (...)".

Ora, as auditorias são instrumentos por excelência da atividade de controle que, se bem realizadas, fornecem informações importantes sobre o desempenho da administração. Portanto, ao desconsiderar o resultado das auditorias (observe-se que o texto é explícito quanto ao resultado e não à simples existência ou trâmite do processo), o tribunal deixa de apresentar informações de natureza pública e de importância para o controle social das ações governamentais e, por consequência, para a promoção da accountability.

Por outro lado, sendo o parecer prévio um documento que compõe o julgamento político das contas do chefe do governo municipal, informações tais como a relação custo-benefício das ações de governo, o nível de consecução dos objetivos e metas e os efeitos e impactos advindos da implantação dos programas de governo, entre outras, permitem à sociedade avaliar e controlar com muito mais precisão e consistência a utilização de seus recursos.

Outra questão evidenciada pela pesquisa diz respeito à falta de informações sistematizadas sobre a atuação dos administradores em relação aos procedimentos de fiscalização promovidos pelo tribunal. A importância dessas informações reside em mostrar à sociedade a ocorrência ou a recorrência dos procedimentos adotados pela administração, em discordância com as normas legais ou com as orientações do próprio tribunal.

Incidentalmente, em um de seus relatórios analisados, o tribunal ofereceu esse tipo de informação. Todavia, poderia ter ido muito além, listando, por exemplo, de forma sistemática e sistematizada, todos os procedimentos de fiscalização realizados ao longo do exercício no município, os resultados dos respectivos julgamentos técnicos e as eventuais sanções aplicadas. Além disso, nada obsta que o tribunal exija, nos relatórios do controle interno que compõem o PCA, informações sobre como a prefeitura vem procedendo em relação às determinações e recomendações oriundas das auditorias e fiscalizações realizadas.

Ademais, abstendo-se de sistematizar e divulgar tais informações nos Repps, o tribunal não só enfraquece seu próprio relatório como instrumento de accountability, como dificulta a ação e a colaboração da sociedade na ampliação da fiscalização e do controle.

Outra questão que revela o formalismo do trabalho do TCE/SC aparece logo no início dos Repps, quando o tribunal verifica a tramitação das leis orçamentárias e a realização de audiências públicas. A análise efetuada limita-se à indicação das datas relativas à tramitação e aprovação das leis e à manifestação quanto ao cumprimento ou não da legislação pertinente em relação aos prazos legais para elaboração e discussão de cada lei, e da realização ou não das respectivas audiências públicas.

O tribunal, neste caso, deixa de avançar em direção à promoção da accountability e pouco contribui para o fortalecimento da participação popular. Mas poderia fazê-lo se passasse a dar mais atenção à realização das audiências públicas.

Como não há qualquer óbice legal que o impeça de realizar a avaliação sobre as condições da participação da sociedade na distribuição e destinação dos recursos públicos (na forma de audiências públicas ou assembleias decorrentes de exigência legal), bastaria ao tribunal solicitar que nos relatórios do controle interno constassem as atas das audiências, bem como 
informações como a quantidade de pessoas que assistiram a cada uma das audiências; os assuntos tratados; as reivindicações formuladas e se foram ou não atendidas e por quais motivos; os compromissos assumidos pela administração etc. Assim, o tribunal obteria e poderia divulgar um conjunto de informações que permitiriam ao cidadão, aos seus representantes e à sociedade em geral confrontar e avaliar a vinculação das ações de governo ao cumprimento dos compromissos assumidos junto à população.

Também merece reflexão a questão das análises do orçamento. O tribunal, neste caso, limita-se à apresentação dos dados consolidados em valores monetários e percentuais referentes aos créditos orçamentários e adicionais do exercício. Não há avaliações sobre as movimentações orçamentárias, principalmente quanto às consequências das anulações de dotações do orçamento aprovado e aos compromissos assumidos em sua elaboração e aprovação. Ou seja, várias dotações programadas e autorizadas na aprovação da LOA vão sendo modificadas (diminuídas ou canceladas) e os correspondentes recursos vão sendo aplicados em outras finalidades, sem que se saibam os motivos por que tais modificações aconteceram. Não apenas não são feitas avaliações, como também não se explicam nem se justificam as alterações orçamentárias promovidas.

Análises e avaliações sobre a execução orçamentária são relevantes na medida em que, ao confrontar a programação (programas, ações e metas físicas) com a respectiva execução, se tem a visão do conjunto das ações de governo e é possível estabelecer a vinculação entre a realização dessas ações e o cumprimento dos compromissos constantes do PPA aprovado, ou seja, é possível estabelecer o grau de responsividade dos agentes públicos.

Mais importante ainda é a questão dos remanejamentos, transposições e transferências orçamentárias. Novamente, em determinado momento de um dos seus relatórios, o tribunal, ao constatar a prática desses atos sem a devida autorização legislativa, afirma que esses atos "referem-se a realocações de recursos por necessidade de reprogramação orçamentária devido à repriorização das ações do governo, diferenciando-se dos créditos adicionais, que têm como fator determinante a necessidade da existência de recursos" (Repp no 5034/2009, item 21.9).

Ainda que o esclarecimento seja oportuno, o fato fundamental é que tais atos de reprogramação orçamentária e repriorização das ações significam que parte dos compromissos políticos e administrativos assumidos com a sociedade e consignados no PPA do município já não será mais cumprida.

Portanto, o que foi planejado e discutido com a população nas audiências públicas, submetido, discutido e aprovado pelo Legislativo municipal e, em última análise, compromissado com a sociedade, está sendo modificado ao exclusivo arbítrio da administração, sem que se saibam os motivos que levaram a tais modificações. E o tribunal, em seu parecer prévio, não faz qualquer análise do quanto foi remanejado (e/ou transposto e/ou transferido), para onde foram os recursos, em detrimento de quais programas, para atender a que outros programas ou prioridades etc.

Se tais informações não estão disponíveis, não é possível estabelecer a vinculação entre a execução orçamentária e o PPA, e não há como saber se as ações de governo são compatíveis 
e estão cumprindo os objetivos e metas constantes do PPA aprovado pelo município, ou se o orçamento foi executado conforme planejado. Portanto, o tribunal estará deixando de dar respostas à sociedade sobre a real utilização dos recursos públicos nos compromissos políticos assumidos pelos governantes e refletidos no PPA.

As análises presentes no parecer prévio são parcas também quando o tribunal trata da apuração do resultado orçamentário e do ajuste das despesas. Embora os dados e informações orçamentários apresentem cunho eminentemente técnico, são de importância fundamental para que se possa compor um quadro realista da gestão municipal no que concerne ao equilíbrio das contas públicas.

Portanto, a apresentação de análises e avaliações sobre o comportamento da receita e da despesa e a repercussão desse comportamento em relação ao exercício em exame, a outros exercícios e mesmo em relação aos demais municípios do estado, oportunizando informações efetivas sobre o desempenho do governo de per se e em comparação ao conjunto dos municípios, seria importante para a formação de uma visão mais abrangente e realista da administração municipal.

Cabe salientar, também, como conclusão deste artigo, que a presente pesquisa ensejou um estudo envolvendo a análise dos pareceres prévios e, nesse aspecto, trouxe à luz e permitiu a discussão de um documento que tem papel fundamental no processo de julgamento político das contas dos chefes de governos municipais e é importante instrumento de controle a serviço da democracia. Não fora a sua realização, talvez a questão nem fosse levantada.

Este, porém, foi um primeiro passo. Há necessidade de mais estudos e pesquisas sobre esse tema, tão pouco explorado no Brasil, principalmente no que se refere ao papel e aos resultados do trabalho dos TCs, conforme ressaltado por Speck (2000), para quem o reduzido número de estudos acadêmicos sobre os TCs é surpreendente, não só pela tradição de mais de um século desses órgãos no Brasil, mas pela centralidade do tema do controle nas ciências sociais.

Assim, replicar o modelo de análise e os procedimentos da pesquisa em pareceres prévios produzidos por outros TCs; comparar os resultados obtidos neste estudo com os de outros TCs; produzir estudos longitudinais que permitam avaliar a evolução dos pareceres prévios ao longo do tempo; investigar a importância que os legislativos municipais atribuem aos pareceres prévios como instrumentos condutores do julgamento dos prefeitos; investigar a importância que os administradores municipais atribuem aos pareceres prévios como instrumentos de controle da própria gestão são algumas sugestões para futuras pesquisas.

Por fim, importa lembrar que, para ampliar e acelerar a evolução política da sociedade brasileira e dar mais consistência à cidadania, há que se insistir na criação e implantação das condições institucionais e na promoção de ações de educação política necessárias ao desenvolvimento dos ideais democráticos e republicanos. Mas é preciso ir além. É preciso promover novas formas de agir e pensar que restabeleçam e reforcem a confiança na capacidade dos governantes e no próprio serviço público, nas suas instituições e nos seus servidores, de darem conta dos cada vez mais complexos desafios impostos pela sociedade, pois só assim se construirá uma democracia realmente sólida e justa. 


\section{Referências}

ABRUCIO, Fernando L.; LOUREIRO, Maria R. Finanças públicas, democracia e accountability. In: ARVATE, Paulo Roberto; BIDERMAN, Ciro (Org.). Economia do setor público no Brasil. Rio de Janeiro: Elsevier; Campus, 2004.

AKUTSU, Luiz; PINHO, José A. G. de. Sociedade da informação, accountability e democracia delegativa: investigação em portais de governos no Brasil. Revista de Administração Pública, Rio de Janeiro, v. 36, n. 5, p. 723-746, set./out. 2002.

ANDRADA, Antônio C. D.; BARROSO, Laura C. Parecer Prévio como instrumento de transparência, controle social e fortalecimento da cidadania. Revista do Tribunal de Contas do Estado de Minas Gerais, v. 77, n. 4, 2010. p. 53-75.

ARANTES, Rogério B.; ABRUCIO, Fernando L.; TEIXEIRA, Marco A. C. A imagem dos tribunais de contas subnacionais. Revista do Serviço Público, v. 56, n. 1, p. 57-83, 2005.

ARATO, Andrew. Representação, soberania popular e accountability. Lua Nova, n. 55/56, p. 85103, 2002.

BARDIN, Laurence. Análise de conteúdo. 4. ed. rev. atual. Lisboa: Edições 70, 2009.

BARROS, Elizabeth F. Auditoria de desempenho nos tribunais de contas estaduais brasileiros: uma pesquisa exploratória. (Dissertação de mestrado) - Faculdade de Economia e Administração, Universidade de São Paulo, 1999. São Luiz: Ed. do autor, 2000.

BEHN, Robert D. O novo paradigma da gestão pública e a busca da accountability democrática. Revista do Serviço Público, v. 49, n. 4, p. 5-45, 1998.

BOBBIO, Norberto. Estado, governo, sociedade: para uma teoria geral da política. 13. ed. Rio de Janeiro: Paz e Terra, 2007.

BOVENS, Mark. Analysing and assessing public accountability. A conceptual framework. European Governance Papers — Eurogov, C-06-01, jan. 2006.

BRASIL. Constituição da República Federativa do Brasil. Brasília: 1988.

BRASIL. Lei Complementar no 101, de 25 de maio de 2000. (Lei de Responsabilidade Fiscal). Estabelece normas de finanças públicas voltadas para a responsabilidade na gestão fiscal e dá outras providências. Brasília: 1988.

CAMPOS, Anna Maria. Accountability: quando poderemos traduzi-la para o português? Revista de Administração Pública, Rio de Janeiro, v. 24, n. 2, p. 30-50, 1990.

DAHL, Robert. Poliarquia: participação e oposição. São Paulo: Edusp, 1997.

DENHARDT, Janet V.; DENHARDT, Robert B. The new public servic: serving, not steering. Expanded edition. Nova York: M. E. Sharp, Inc., 2007.

FAORO, Raymundo. Os donos do poder. Formação do patronato político brasileiro. 3. ed. rev. São Paulo: Globo, 2001. 
FERRAZ, Luciano. Due process of law e parecer prévio das cortes de contas. Revista Diálogo Jurídico, ano 1, n. 9, 2001. Disponível em: <www.direitopublico.com.br/pdf_9/DIALOGO-JURIDICO-09DEZEMBRO-2001-LUCIANO-FERRAZ.pdf> . Acesso em: 26 jul. 2011.

FURTADO, José de R. C. Os regimes de contas públicas: contas de governo e contas de gestão. Revista do Tribunal de Contas da União, v. 35, n. 109, p. 61-89, 2007.

GAMBOGI, Luís C. O parecer prévio nas contas do executivo municipal e o direito aos recursos a ele inerentes. Revista do Tribunal de Contas do Estado de Minas Gerais, v. 34, n. 4, 2000. Disponível em: <www.tce.mg.gov.br/revista>. Página impressa em: 12 jun. 2009.

GIACOMONI, James. Orçamento público. 14. ed. rev. São Paulo: Atlas, 2009.

GUERRA, Evandro M. Os controles externo e interno da administração pública. 2. ed. Belo Horizonte: Fórum, 2005.

HEIDEMANN, Francisco G.; SALM, José F. (Org.). Políticas públicas e desenvolvimento: bases epistemológicas e modelos de análise. Brasília: Editora UnB, 2009.

INSTITUTO DE PESQUISA ECONÔMICA APLICADA - IPEA. Estado, instituições e democracia: república. Livro 9, v. 1. Brasília: Ipea, 2010.

JAGUARIBE, Helio et al. Sociedade, Estado e partidos na atualidade brasileira. São Paulo: Paz e Terra, 1992.

KALDOR, Mary. Civil society and accountability. Journal of Human Development, v. 4, n. 1, p. 1-27, 2003.

KENNEY, Charles D. Horizontal accountability: concepts and conflicts. In: MAINWARING, Scott; WELNA, Christopher (Ed.). Democratic accountability in Latin America. Oxford: Oxford University Press, 2005. (Oxford Studies in Democratization Series)

KOPPELL, Jonathan G. S. Pathologies of accountability - Icann and the challenge of "multiple accountabilities disorder". Public Administration Review, v. 65, n. 1, p. 94-108, 2005.

KRONBAUER, Clóvis A. et al. Análise de inconsistências apontadas pelo TCE/RS em auditorias municipais: estudo do controle externo da gestão pública. Revista de Contabilidade e Organizações, v. 5 n. 12, p. 48-71, 2011.

LOUREIRO, Maria R.; TEIXEIRA, Marco A. C.; MORAES, Tiago C. Democratização e reforma do Estado: o desenvolvimento institucional dos tribunais de contas no Brasil recente. Revista de Administração Pública, Rio de Janeiro, v. 43, n. 4, p. 107-119, 2009.

LOUREIRO, Maria R.; TEIXEIRA, Marco A. C.; PRADO, Otávio. Construção de instituições democráticas no Brasil contemporâneo: transparência das contas públicas. O\&S, v. 15, n. 47, p. 107-119, 2008.

MAINWARING, Scott. Introduction: democratic accountability in Latin America. In: MAINWARING, Scott; WELNA, Christopher (Ed.). Democratic accountability in Latin America. Oxford: Oxford University Press, 2005. (Oxford Studies in Democratization Series) 
MEIRELLES, Hely L. Direito administrativo brasileiro. 33. ed. São Paulo: Malheiros, 2007.

O’DONNELL, Guillermo. Accountability horizontal e novas poliarquias. Lua Nova, n. 44, p. 27-54, 1998.

O’DONNELL, Guillermo. Accountability horizontal: la institucionalización legal de la desconfianza política. Revista Española de Ciencia Política, n. 11, p. 11-31, 2004.

PINHO, José A. G. de; SACRAMENTO, Ana R. S. Accountability: já podemos traduzi-la para o português? Revista de Administração Pública, Rio de Janeiro, v. 43, n. 6, p. 1343-1368, nov./dez. 2009.

PRZEWORSKI, Adam; CHEIBUB, José A. Democracia, eleições e responsabilidade política. Revista Brasileira de Ciências Sociais, v. 12, n. 35, p. 1-20, 1997.

RICHARDSON, Roberto J. et al. Pesquisa social: métodos e técnicas. São Paulo: Atlas, 1999.

ROCHA, Arlindo C. Accountability na administração pública: a atuação dos tribunais de contas. In: ENCONTRO NACIONAL DA ANPAD, XXXIII, São Paulo, 2009. Anais... São Paulo: ANPAD, 2009. p. 1-16.

ROCHA, Arlindo C. Accountability na administração pública: modelos teóricos e abordagens. Contabilidade, Gestão e Governança, Brasília, v. 14, n. 2, p. 82-97, 2011.

SANTA CATARINA. Constituição do Estado de Santa Catarina. Florianópolis, 1989.

SANTA CATARINA. Lei Complementar no 202, de 15 de dezembro de 2000. Institui a Lei Orgânica do Tribunal de Contas do Estado de Santa Catarina e adota outras providências. Florianópolis, 2000 .

SCHEDLER, Andreas. Conceptualizing accountability. In: SCHEDLER, Andreas; DIAMOND, Larry; PLATTNER, Marc F. (Ed.). Self-restraining State: power and accountability in new democracies. Boulder: Lynne Rienner Publishers, 1999.

SILVA, Márcio H. da. A dualidade de julgamento das contas públicas do chefe do Poder Executivo municipal. Revista do Tribunal de Contas do Estado de Minas Gerais, v. 34, n. 4, 2000. Disponível em: <www.tce.mg.gov.br/revista>. Página impressa em: 19 abr. 2010.

SMULOVITZ, Catalina; PERUZZOTTI, Enrique. Societal and horizontal controls: two cases of a fruitful relationship. In: MAINWARING, Scott; WELNA, Christopher (Ed.). Democratic accountability in Latin America. Oxford: Oxford University Press, 2005. p. 309-331. (Oxford Studies in Democratization Series)

SPECK, Bruno W. Inovação e rotina no Tribunal de Contas da União: o papel da instituição superior de controle financeiro no sistema político-administrativo do Brasil. São Paulo: Fundação Konrad Adenauer, 2000.

STIVERS, Camilla. Democratic knowledge - the task before us. Administration \& Society, v. 42, n. 2, p. 248-259, 2010.

TRIBUNAL DE CONTAS DA UNIÃO. Instrução Normativa - TCU № 63, de 1ํ de setembro de 2010. Estabelece normas de organização e de apresentação dos relatórios de gestão e das peças comple- 
mentares que constituirão os processos de contas da administração pública federal, para julgamento do Tribunal de Contas da União, nos termos do art. 7ํ da Lei no 8.443, de 1992. Brasília, 2010.

TRIBUNAL DE CONTAS DO ESTADO DE SANTA CATARINA. Decisão Normativa $n^{\circ}$ TC-06/08, de 17 de dezembro de 2008. Estabelece critérios para apreciação, mediante parecer prévio, das contas anuais prestadas pelos Prefeitos Municipais, e o julgamento das contas anuais dos Administradores Municipais, e dá outras providências. Florianópolis, 2008.

TRIBUNAL DE CONTAS DO ESTADO DE SANTA CATARINA. Resolução TC nํㅜ TC-06/2001, de 11 de setembro de 2002. Aprova o Regimento Interno do Tribunal de Contas do Estado de Santa Catarina. Florianópolis, 2002.

TRIBUNAL DE CONTAS DO ESTADO DE SANTA CATARINA. Revista Controle Público, Florianópolis, TCE/SC, v. 2, n. 5, 2009.

TRIBUNAL DE CONTAS DO ESTADO DE SANTA CATARINA. Revista Controle Público, Florianópolis, TCE/SC, v. 3, n. 9, 2010.

Arlindo Carvalho Rocha é professor do Departamento de Ciências Econômicas do Centro de Ciências da Administração e Socioeconômicas da Universidade do Estado de Santa Catarina (DCE/Esag/Udesc) e pesquisador do Grupo Politeia — Coprodução do Bem Público: Accountability e Gestão. E-mail: arlindo. rocha@udesc.br. 
